\title{
Un proyecto jesuita a favor de la democracia:
} el Partido Católico Nacional y las organizaciones sociopoliticas promovidas por la Compañia de Jesús en México, durante la segunda década del siglo XX

\section{A Jesuit Project in Favor of Democracy: \\ The National Catholic Party and Socio-Political \\ Organizations Promoted by the Company of Jesuis in México, During the Second Decade of the Twentieth Century}

\author{
RAFAel IgnACIO ROdRÍGUeZ JimÉnEZ \\ Universidad lberoamericana León \\ México \\ Correo: Ignacio.rodriguez@iberoleon.mx \\ https://orcid.org/0000-000I-939I-7667 \\ DOI: 10.48102/hyg.vi57.370
}

Artículo recibido: I I/08/2020

Artículo aceptado: 24/03/202 I

\section{Abstract}

During the first decade of the Twentieth century, right before the Mexican Revolution, some Jesuits had a sociopolitical project. What extent of these Jesuit priests' political implication in that first part of the Revolution? In this work, I expose how Francisco I. Madero confronted this project at the beginning of the Mexican Revolution and I display the sociopolitical alternatives started by the Jesuits after the murder of Madero. The center topic on this essay are three fundamental lines: the implementation of Social Catholicism in Mexico, prompted by Catholic hierarchy; social Catholicism as a way to crystalize the Christian Democracy's doctrine; and the role played by the Society of Jesus as a 
linking network, which organized the many catholic militants' efforts throughout the country. As an example of the sociopolitical action taken by the Jesuits during such stage of the Revolution, one could name the forming of the Catholic National Party.

Key words: Jesuits; Political Participation; Mexican Revolution; Christian Democracy; Social Catholicism.

\section{Resumen}

En la primera década del siglo $\mathrm{xx}$, hay un proyecto sociopolítico de algunos jesuitas, previo a la Revolución mexicana. ¿En qué medida los jesuitas estaban implicados políticamente durante la primera etapa de la Revolución? En este estudio muestro cómo este proyecto es confrontado con Francisco I. Madero, al principio de la Revolución, y las alternativas sociopolíticas que inician los jesuitas después del asesinato de Madero. El tema predominante de este escrito radica en tres líneas fundamentales: la implementación del catolicismo social en México impulsada por la jerarquía católica; el catolicismo social como una forma de cristalizar la doctrina de la democracia cristiana propuesta por León XIII; y el papel de la Compañía de Jesús como instancia articuladora que organiza los esfuerzos de muchos militantes católicos en el país. Como ejemplo de la acción sociopolítica desarrollada por los jesuitas en ese momento se puede señalar la fundación del Partido Católico Nacional.

Palabras clave: jesuitas, participación política, Revolución mexicana, democracia cristiana, catolicismo social.

\section{INTRODUCCIÓN}

Gl objetivo de este estudio es indagar las formas en las que Jun proyecto social y politico que tenian algunos jesuitas es
confrontado con Francisco I. Madero, al inicio de la Revolución mexicana. Hay que aclarar, desde este momento, que es obvio que cada vez que me refiera a los jesuitas, no hablo de la totalidad de los miembros de la Compañía en México, sino de aquellos que tienen un papel más significativo en el desarrollo de este proyecto, y otros que les siguen a lo largo de la Provincia; aunque hacia 
fuera de la institución serán identificados como si todos los jesuitas llevaran adelante dicho proyecto. ${ }^{1}$

Las preguntas que guían esta investigación se interesan en indagar si los jesuitas estaban implicados políticamente durante la primera etapa de la Revolución; qué papel jugó la Compañía en la formación del Partido Católico; cuáles jesuitas destacaron más en su actividad sociopolítica; qué implicaciones políticas tuvieron algunas organizaciones sociales dirigidas por la Compañía de Jesús después del asesinato de Madero; y qué relaciones hubo entre la Orden de san Ignacio y los revolucionarios.

La lectura de la Revolución maderista, desde el punto de vista de los miembros de la Compañía -quienes fueron afectados por la misma Revolución-, permite una profundización en los acontecimientos y una interpretación nueva y diferente. El hecho de haber rescatado y estar fundamentado sobre todo en textos inéditos, confiere otro valor a este artículo. Tuve acceso a dos archivos que fueron claves para este trabajo: el Archivo de la Provincia Mexicana de la Compañía de Jesús, y el archivo del padre General en Roma. Asimismo, pude revisar la documentación correspondiente al tema en otros países. ${ }^{2}$ Con esta información y con el empleo de una teoría y metodología adecuada al tema que abordé, ${ }^{3}$

${ }^{1}$ Hace falta un análisis más a fondo de la situación de la Compañía de Jesús en México durante la primera etapa de la Revolución. Se desconoce la posición que sostuvo la Orden frente a Francisco I. Madero. Esto puede dar luz a lo que se ha escrito sobre el papel de la Iglesia en esa etapa tan importante de la vida del país. ${ }^{2} \mathrm{He}$ podido consultar documentos de otros archivos importantes. Nacionales: Archivo General de la Nación (AGN) y Archivo Jesuita de la Guerra Cristera (AJGC), en el ITESo. Del extranjero: Georgetown University Library (GUL). Algunos de los acervos que pude revisar son de acceso restringido, como el Archivo Histórico de la Provincia Mexicana de la Compañía de Jesús (AHPM), el Archivum Romanum Societatis Iesu (ARSI), y el Archivo de la Provincia jesuítica de Maryland que se encuentra en Georgetown (GUL), lo que confiere un valor particular a esta investigación.

${ }^{3}$ El método que seguí fue este: lectura de los textos de bibliografía básica y elaboración de las correspondientes fichas de investigación, con lo que pude construir un primer esquema de interpretación de los acontecimientos; después realicé algunas entrevistas, lo que me obligó a ir ajustando el esquema inicial; luego me 
me fue posible escribir una narración documentada sobre la actuación de los miembros de la Orden.

Al considerar a la Iglesia como parte históricamente integrante de la realidad cultural mexicana, resulta fundamental rescatar el papel que ha jugado en el desarrollo del proceso social de nuestro país. Una manifestación clara de la presencia de la Iglesia a través de la Compañía en la sociedad mexicana es el aporte de los jesuitas en la formación de la identidad nacional en el siglo XVIII. Si se tiene en cuenta el papel tan significativo que jugó la Compañía de Jesús en el México virreinal, como forjadora de la mentalidad criolla, y como una institución que más tarde dio gran impulso a la educación y acción social en el país, en el siglo XIX, después de su restablecimiento en 1816, también será de gran importancia analizar el papel de los miembros de la Orden durante una época tan rica y discutida como fue la Revolución de Madero. Se trató de un periodo de profundos cambios para la sociedad mexicana, que dejará un sello indeleble en la Compañía de Jesús.

Como ejemplos de algunas instituciones que encarnan la acción sociopolítica desarrollada por los jesuitas durante esta etapa de la Revolución, se pueden señalar la fundación del Partido Católico Nacional y de la Unión de Damas Católicas Mexicanas, la dirección de la Liga Nacional de Estudiantes Católicos y de los Centros de Estudiantes Católicos, la formación de sindicatos católicos y la creación de la Asociación Católica de la Juventud Mexicana (АСJM).

Una de mis intenciones es ir destacando lo que se sale de la norma, los contrastes que he ido encontrando en la documenta-

lancé a la búsqueda de documentación en los archivos señalados y, con la información que fui adquiriendo ahí, pude elaborar una redacción más completa de mi texto, apoyado también por los aportes de varios asesores. En cuanto a las fuentes del contexto mexicano, tuve como referentes a autores como Friedrich Katz, Robert Quirk, Ariel Rodríguez Kuri, John Womack y Luis González y González, autores de grandes obras sobre la Revolución que me ayudaron a situar mis análisis. Posteriormente acudí a los planteamientos de algunos teóricos, y con sus reflexiones pude problematizar mi análisis; por último, realicé la redacción definitiva de este trabajo. 
ción referente a la situación de la Compañía durante la primera etapa de la Revolución. Porque lo esperado en un México, al fin y al cabo heredero del liberalismo del siglo xIx, era la polarización de la relación Iglesia-Estado, y más con un Estado que, durante la Revolución, fue exacerbando la herencia liberal y radicalizando sus posturas en contra del clero.

El tema predominante de este escrito radica en tres líneas fundamentales: el catolicismo social como una forma de cristalizar la doctrina de la democracia cristiana propuesta por León XIII a partir de su encíclica Rerum Novarum; la implementación del catolicismo social en México impulsada por la jerarquía católica; y el papel de la Compañía de Jesús como instancia articuladora que organiza los esfuerzos de muchos militantes católicos en el país.

Algunos de los ejes temáticos de esta investigación son los siguientes: al final del porfiriato había muchos malestares, entre ellos, el debido al acaparamiento de la riqueza del país en unas cuantas manos, mientras la gran masa del pueblo vivía en suma pobreza. Otro problema significativo era la falta de participación política de los jóvenes. Ante el descontento social debido a esta situación de injusticia que se había generado en el país, y que va a desembocar en la Revolución mexicana, la respuesta jesuita se manifestará en una postura activa y beligerante de algunos miembros de la Orden. ${ }^{4}$

La fuente privilegiada de esta investigación ha sido la correspondencia entre los Provinciales ${ }^{5}$ y los padres Generales, ${ }^{6}$ y la de los mismos jesuitas. Hay que subrayar la importancia de esta do-

\footnotetext{
${ }^{4}$ Es claro que, durante el periodo que estudio, la Compañía no tiene el monopolio de la acción social; pero, junto con algunos grupos de la Iglesia, desarrolla una participación distinta, más social y política, que la mayoría del clero frente a la Revolución. La generalidad de los sacerdotes y religiosos asume una postura de resistencia pasiva ante el sesgo anticlerical que va tomando el movimiento desde sus inicios.

${ }^{5}$ El Provincial es un superior mayor en la Compañía de Jesús, encargado de una Provincia. Es nombrado por el General.

${ }^{6}$ El General es el superior de toda la Compañía de Jesús, después del Papa. Es elegido por la Congregación General, equivalente al Capítulo General en otras órdenes religiosas. Es la máxima autoridad dentro de la Compañía de Jesús.
} 
cumentación, pues es confidencial en la Orden y se utiliza como órgano de gobierno; y no fue fácil para mí poder revisarla. Lo pude hacer gracias a un permiso especial que me concedió el P. Peter Hans Kolvenbach, entonces superior general de los jesuitas, y con esto tuve el privilegio de consultar estos archivos. Aunque la mayoría de los documentos están en latín, lo manejo con fluidez.

Este estudio recupera una memoria documental que propiamente no se había podido consultar; los archivos de la Compañía de Jesús correspondientes a la Revolución estuvieron cerrados hasta hace cinco años. Los autores de este conjunto de documentos son jesuitas. Su visión de los acontecimientos está condicionada por su lugar social y su tiempo, y la mayoría de las veces es muy parcial, interesada en asuntos muy concretos. $\mathrm{He}$ enriquecido estas fuentes prioritarias al recuperar, por medio de entrevistas, los recuerdos de esta etapa desde los testimonios de algunos historiadores miembros de la Compañía.

Mi "ventaja" se debe a haber podido tener acceso a la documentación disponible sobre el tema. Ni Gerardo Decorme ni José Gutiérrez Casillas, principales historiadores de la Compañía en México, tuvieron esta oportunidad. Y también a la formación contemporánea del investigador: esto me hace tomar una distancia crítica de los acontecimientos y me lleva a hacer un trabajo profesional de las fuentes, sin caer en la hagiografía o el ocultamiento. Además, siendo yo jesuita, no estoy haciendo una interpretación oficial ni apologética; el objetivo de este trabajo es realizar una labor académica de calidad; no tiene una intencionalidad institucional, lo que le concede un valor particular.

La interpretación que se haga de un hecho histórico, en este caso la Revolución, desde un lugar social concreto, institucional, religioso o de clase, lo matiza de manera distinta; en ese sentido, este estudio, siguiendo a Michel de Certeau, no pretende ser sino una investigación crítico reflexiva. ${ }^{7}$

${ }^{7}$ Vid. Michel de Certeau, La escritura de la historia, capítulo introductorio, en donde rinde homenaje al historiador Michelet, enterrador de los muertos, con 
A finales de 1910, México festeja el centenario de su Independencia, y muestra al mundo el progreso y la estabilidad que el régimen porfirista supuestamente ha logrado, al mismo tiempo que comienza una de las mayores rupturas políticas y sociales del país: la Revolución, que toma de improviso a toda la sociedad mexicana, incluida la Compañía de Jesús. El presidente Díaz lleva a cuestas 80 años; poco antes, en 1908, el viejo caudillo había declarado al periodista norteamericano, James Creelman, su intención de dejar el poder en cuanto terminara su periodo de gobierno; incluso, afirmó que vería como una "bendición" la aparición de un partido opositor. ${ }^{8}$ A raíz de esta entrevista aparece, entre otras publicaciones, La sucesión presidencial en 1910 de Francisco I. Madero. ${ }^{9}$

A última hora, Díaz vuelve a postularse por enésima vez. En junio de 1910 Madero declara que si las elecciones no se ganan legalmente se verá obligado a ir por cauces no legales. Por ello es encarcelado en San Luis Potosí; pero gracias al ministro José Ives Limantour puede escapar a Texas. Desde allá lanza el Plan de San Luis, a principios de noviembre de 1910, en el que denuncia como fraudulentas las recientes elecciones presidenciales, así como las del Congreso y las judiciales; se declara como Presidente provisional, convoca a la rebelión y al desconocimiento de las autoridades a partir del 20 de noviembre, y promete elecciones democráticas para un nuevo gobierno.

La correspondencia oficial del provincial jesuita, P. Tomás Ipiña, no se mantiene ajena a estos acontecimientos. En una carta del 26 de noviembre de 1910 al padre General de la Compañía de Jesús, Francisco Xavier Wernz, menciona un brote revolucio-

\footnotetext{
lo que cumple una función de duelo con los antepasados y se abre paso en el presente para descubrir nuevas posibilidades. Y, desde luego, el capítulo II, sobre La operación historiográfica.

${ }^{8}$ Cfr. Luis González y González, Obras. El siglo de las luchas, p. 146.

${ }^{9}$ Cfr. Ibidem, p. 148.
} 
nario sin darle mucha importancia. ${ }^{10}$ Después, el 11 de diciembre, escribe al P. Matías Abad, asistente ${ }^{11}$ de España, ${ }^{12}$ que los antigobiernistas no inspiran temor. ${ }^{13}$

Aunque el 1 de diciembre de 1910 Díaz comienza un nuevo mandato, en enero de 1911, en las montañas de Chihuahua ya hay más de 2000 guerrilleros maderistas. ${ }^{14} \mathrm{La}$ situación rebasa al ejército porfirista. En febrero, Madero reúne a sus seguidores, cuyo principal cabecilla es un transportista, Pascual Orozco, y, entre sus lugartenientes está Francisco Villa.

Para entonces, el Provincial jesuita no sabe aún cómo calificar la subversión política: "No sé qué decir acerca de la perturbación de la República, aún persistente en el estado de Chihuahua; la mayoría tiene desconfianza de los que la encabezan; el temor parece prevalecer en todos; aunque da la impresión que los que se oponen al presente régimen no tienen nada contra la religión, sin embargo hay desconfianza" ${ }^{15}$ Poco después, a principios de abril, añade con mayor preocupación: "La perturbación en la República se siente que va creciendo, al igual que la rebelión armada contra el gobierno, a la que parece que apoyan los Estados Unidos. Algunos opinan que se vienen grandes cambios, quizá adversos para la Iglesia y la religión". ${ }^{16}$

En cuestión de meses, la insurrección nacional que Madero había pretendido es ya una realidad. ${ }^{17} \mathrm{La}$ caída de Ciudad Juárez a manos de Pascual Orozco el 10 de mayo de 1911, es la estocada final contra el régimen. Madero instala ahí su gobierno provi-

\footnotetext{
${ }^{10}$ Arsi. División Nuova Compagnia, Sección I: Epistolae Provincia Mexicana, Tomás Ipiña, S. I. “Carta al P. Wernz”, Mex. 1003, vi: 1910, 31, 26/11/1910, p/u. ${ }^{11}$ Consejero del General. Especialmente encargado de un grupo de Provincias que forman una "Asistencia”. Es elegido por la Congregación General.

${ }^{12}$ En 1910 la Provincia de México estaba dentro de la Asistencia de España.

${ }^{13}$ Cfr. arsi... vi, Ipiña "Carta al P. Matías Abad, Assist. Hisp. México", 34, 11/12/1910, p. 1 .

${ }^{14}$ Cfr. John Jr. Womack, “La Revolución mexicana”, pp. 149-151.

${ }^{15}$ ARSI... VII, Ipiña "Carta al P.Wernz", 10, 13/02/1911, p. 2.

${ }^{16}$ ARsi... viI, Ipiña "Carta al P.Wernz", 11, 08/04/1911, pp. 1-2.

${ }^{17}$ Cfr. Womack, "La Revolución mexicana...", op. cit., p. 152.
} 
sional. El presidente norteamericano, William Taft, ordena la movilización de veinte mil soldados a la frontera con Chihuahua. Limantour, temeroso de que suceda una intervención para poner fin a la inestabilidad en México, sugiere al Presidente negociar con los levantados. ${ }^{18}$

En la correspondencia del Provincial aparece que, a principios de mayo de 1911, la inestabilidad política ya le afecta directamente:

La Revolución [por primera vez la llama así] ha avanzado mucho. El gobierno ha [...] planteado un armisticio con el Jefe de la Revolución. [...] Puede firmarse la paz [...]. Puede recrudecerse la lucha, seguida tal vez, de una guerra con nuestros poderosos vecinos... [Con relación a los alzamientos en Coahuila, añade:] En el combate que precedió a la toma de la ciudad de Parras por los revolucionarios, quedó nuestra iglesia ${ }^{19}$ inutilizada; [...]. Quedaron ilesos los nuestros que se expusieron e hicieron proezas en asistir a los heridos de ambos partidos combatientes [...]. ${ }^{20}$

En este punto quiero resaltar un aspecto importante que personifican los jesuitas sobre el papel de la Iglesia en el mundo moderno: al auxiliar a los heridos de los dos grupos combatientes queda claro que la Iglesia está abierta a los opuestos en el mundo civil; que da sus servicios por igual a quienes están matándose en el terreno de lo político. Es el punto donde se reúnen los opuestos; en su seno otorga un reconocimiento a cada uno por su afinidad religiosa. A esto se podría llamar el "civilismo" que ejerce la Iglesia, de 1910 a 1914.

El 21 de mayo, las partes beligerantes firman los Tratados de Ciudad Juárez; se estipula que Díaz abandone su cargo, por lo que

${ }^{18}$ Cfr. Friedrich Katz, Pancho Villa, vol. I, p. 131.

${ }^{19}$ Se refiere a la Iglesia de San Ignacio en Parras, que se había abierto en 1895. AHpm. Iv, Rafael Ignacio Rodríguez Jiménez, "Cronología de Fundaciones de la Provincia de México (1572-1997)”, p. 15.

${ }^{20}$ ARsı... viI, Ipiña "Carta al P. Matías Abad, Assist. Hisp.", 14, México, 01/05/1911, pp. 1-2. 
dimite el 25 de mayo. En su lugar se nombra a Francisco León de la Barra, en espera de celebrar elecciones en octubre. Madero entra triunfante, como el "apóstol de la democracia", a la capital del país el 7 de junio de 1911.

A continuación, presento el desarrollo del argumento de este artículo: cómo se expresa el catolicismo social en México. Algunos jesuitas participan tanto en la fundación de los Círculos Católicos, ${ }^{21}$ desde los inicios de la década de los ochenta del siglo XIX, como en las Semanas Sociales, Dietas ${ }^{22}$ Obreras y Congresos Católicos que se llevaron a cabo en el ámbito de la Iglesia institucional, a partir de 1902. La organización de estas actividades político-sociales de la Iglesia, conocidas como catolicismo social, derivó en la fundación del Partido Católico Nacional, en 1911. Posteriormente surgirán otras organizaciones sociopolíticas impulsadas por los jesuitas como la Asociación Católica de la Juventud Mexicana y los Sindicatos Católicos.

\section{Bernardo BergoËnd, S. I., Un Líder paradigmático}

El conflicto con Madero no toma por sorpresa a todos los jesuitas. El P. Bernardo Bergoënd, en Guadalajara, plantea, de cara a las elecciones de 1910, la importancia de que los católicos puedan tener una intervención política organizada, y propone a los Operarios Guadalupanos ${ }^{23}$ tapatíos, la necesidad de formar un partido

${ }^{21}$ Los Círculos Católicos dirigidos por los jesuitas provienen de las Congregaciones Marianas (ССмM) y su propósito es desarrollar el contenido de acción social incluido en los objetivos de las mismas сCмM.

${ }^{22}$ En sentido político, una Dieta es una asamblea formal deliberativa de un Estado. La palabra deriva del latín medieval dietas, cuya raíz es dies (día). El término siguió siendo utilizado en este sentido debido a la regularidad con que se reunían tales asambleas.

${ }^{23}$ Los Operarios Guadalupanos se fundan en Oaxaca el 21 de enero de 1909, como Círculo de Estudios Católicos-Sociales de Santa María de Guadalupe. Cfr. Manuel Ceballos Ramírez, "Conservadores e intransigentes en la época de 
católico $^{24}$ que, fundamentado en la democracia cristiana, favoreciera a las clases "inferiores". ${ }^{25}$ La democracia cristiana se entendía entonces como la acción popular cristiana que, según León XIII, consiste en "aquel ordenamiento civil en el cual todas las fuerzas sociales, jurídicas y económicas, en la plenitud de su desarrollo jerárquico, cooperan proporcionalmente al bien común, refluyendo en último resultado en preponderante ventaja de las clases inferiores". ${ }^{26}$

Hay que tener en cuenta que el concepto de "democracia cristiana” es polisémico y en esa época se emplea de manera ambigua; además, existe un interés político en el contexto: la emancipación total de los Estados modernos, en un mundo que se seculariza con rapidez. Por ejemplo, para Pío X, la democracia cristiana no debe inmiscuirse en política. ${ }^{27}$ Para Federico Ozanán, en Francia, la democracia cristiana debe iniciar como movimiento social, para luego evolucionar hacia la formación de los partidos políti$\cos ^{28}$ Severino Aznar, ${ }^{29}$ en España, la concibe como la acción de

Porfirio Díaz", p. 134. La organización estaba formada por militantes de las elites o de las clases medias aliados con obreros, campesinos y artesanos. Los Operarios también son llamados "Sociólogos Guadalupanos". Cfr. Manuel Ceballos Ramírez, "Los Operarios Guadalupanos: intelectuales del catolicismo social mexicano 1909-1914”, p. 66. Su propósito era elaborar un proyecto católico autónomo basado en la democracia cristiana, contra la corriente conservadora -la mayoría de los militantes católicos-, que prefería que siguiera el modus vivendi porfiriano. Cfr. Elisa Cárdenas Ayala, El Derrumbe: Jalisco, microcosmos de la Revolución mexicana, pp. 254 y 262.

${ }^{24}$ Cfr. Robert E. Quirk, The Mexican Revolution and the Catholic Church, 19101929, p. 18.

${ }^{25}$ Cfr. Moisés González Navarro, Cristeros y agraristas en Jalisco, vol. I. p. 84.

${ }^{26}$ Andrés Barquín y Ruiz, Bernardo Bergöend [sic], S. J., p. 17.

${ }^{27}$ Motu proprio de 1903.

${ }^{28}$ Cfr. <http://www.chasque.net/pdc/cayota.htm>. Consultada el $1^{\circ}$. de junio de 2019.

${ }^{29}$ Severino Aznar. Nació en 1870. Sociólogo, académico y periodista. En 1907 funda en Zaragoza La Paz Social, revista del sindicalismo católico. También organiza Semanas Sociales. En 1921 funda el Grupo de la Democracia Cristiana. Murió en Madrid en 1959. Cfr. <http://www.enciclopedia-aragonesa.com/voz. asp?voz_id=1692>. Consultada el $1^{\circ}$ de septiembre de 2015 . 
los católicos encaminada a la difusión teórica y a la incorporación práctica de los principios sociales del catolicismo a las costumbres, leyes e instituciones procurando la justicia social para todos y, de un modo especial, para las clases necesitadas. ${ }^{30}$ Siempre queda la duda de si se está utilizando ortodoxamente el concepto de democracia cristiana. ${ }^{31}$

Las nuevas ideas y demandas a favor de la justicia, la igualdad y el reconocimiento del voto calan muy hondo en México, sobre todo en las poblaciones urbanas, y les llevan a nuevas formas de hacer política. ${ }^{32}$ En relación con este punto considero inaceptable la afirmación generalizante de Elisa Cárdenas de que durante el siglo XIx los obispos prohibían que los católicos participaran en la vida política del país; ${ }^{33}$ en cambio, me parece más lúcida la aportación de Marta Eugenia García Ugarte, quien aclara que, ya desde 1877, el arzobispo de México, Pelagio Antonio Labastida y Dávalos decide aplicar una medida que ya había solicitado a Roma: que los católicos pudieran participar en política y ocupar puestos en la administración pública. ${ }^{34}$ Aunque ciertamente, a principios del siglo xx, la mayor parte de la jerarquía mexicana había dejado para un momento posterior la formación de un partido político católico, siguiendo los deseos de Porfirio Díaz, y debido a las relaciones que guardaba con el Estado liberal mexicano. ${ }^{35}$

Por solicitud de los Operarios Guadalupanos e inspirado en el Partido Acción Liberal Popular de Francia, Bergoënd concibe un proyecto: "La Unión Político-Social de los Católicos Mexi-

${ }^{30}$ Cfr. <http://www.arbil.org/(44)azna.htm RevistaARBIL, no 44 >. Consultada el $1^{\circ}$. de junio de 2019.

${ }^{31}$ Cfr. Cárdenas Ayala, El Derrumbe: Jalisco, op. cit., pp. 238-273, passim.

${ }^{32}$ Cfr. Ariel Rodríguez Kuri, Historia del desasosiego: la Revolución en la ciudad de México, 1911-1922, p. 21.

${ }^{33}$ Cfr. Cárdenas Ayala, El Derrumbe: Jalisco, op. cit., p. 240.

${ }^{34}$ Cfr. Marta Eugenia García Ugarte, Poder politico y religioso: México, siglo XIX, t. 1 , p. 39.

${ }^{35}$ Cfr. Cárdenas Ayala, El Derrumbe: Jalisco, op. cit., p. 260. 
canos". ${ }^{36}$ El jesuita define así el programa de justicia social de la Unión, ante la crítica situación del país: "Queremos emprender en toda forma una acción social de tal naturaleza que disminuya las causas permanentes de miserias y de injusticias que aquejan a nuestro pueblo [...], pero como la acción social poco podrá, o nada, sin una legislación social, y la legislación social no se alcanza sin la acción politica, nos lanzaremos sin miedo al campo de batalla político". ${ }^{37}$ Bergoënd diseñó (en compañía del licenciado Miguel Palomar y Vizcarra) y asesoró al Partido Católico Nacional (PCN)..$^{38}$ Aunque no fue el director del PCN, sí "intervino de modo directo [...] para asentar y establecer las bases" de éste. ${ }^{39}$ En el trasfondo de esta nueva situación que van a enfrentar los jesuitas con la Revolución maderista están influyendo el antiguo conflicto religioso y las leyes anticlericales que vienen desde el siglo xix; por eso, surge en la Compañía el interés de formar un partido, para poder modificar la Constitución. ${ }^{40}$ El 3 de mayo de 1911 se celebra en la Ciudad de México la asamblea constitutiva del PCN. ${ }^{41}$ Después,

${ }^{36}$ Cfr. Antonio Ríus Facius, Bernardo Bergoend [sic], S. J.: guía y maestro de la juventud mexicana, pp. 20-21.

${ }^{37}$ Barquín y Ruiz, Bernardo Bergöend, S. J., op. cit., p. 20. Énfasis del original.

${ }^{38}$ Cfr. Gerardo Decorme, S. I., Historia de la Compañia de Jesús: en la República Mexicana. De Madero a Calles 5 oct. 1910 - 1 diciembre 1924: Dispersión y Reorganización", p. 1.

${ }^{39}$ Miguel Palomar y Vizcarra, "Ha muerto el padre Bergoënd", p. 1

${ }^{40}$ Para comprender este proceso de los inicios del catolicismo social mexicano, tenemos que remontarnos al conflicto religioso entre la Iglesia y el Estado durante el siglo XIX, cuando se enfrenta el anticlericalismo de Estado ( $C f$ r. Jean Meyer, Historia de los cristianos en América Latina: siglos XIX y XX, pp. 77-80) contra el antiliberalismo intransigente de una Iglesia fuerte y poderosa, lo que provoca que ésta apoye con frecuencia movimientos contrarios a los gobiernos liberales. Esta contradicción se suaviza con la llegada al poder de Porfirio Díaz y la aceptación formal de algunos acuerdos con él por parte del Episcopado para garantizar la paz y el orden social. Estos acuerdos implican que no se apliquen las Leyes de Reforma de una manera radical, a cambio de suspender la beligerancia de la Iglesia, lo que da como resultado el establecimiento de un modus vivendi que se caracteriza por la no agresión y la cordialidad, sobre todo en algunas regiones del país.

${ }^{41}$ Vid. José Bravo Ugarte, S. I., Compendio de historia de México: hasta 1964, p. 264. 
Madero lo apoya y lo considera el "primer fruto de las libertades conquistadas", ${ }^{42}$ luego de firmar la paz con Porfirio Díaz.

Carlos Heredia, S. I., un Personaje QUe rompe los esquemas

Otro jesuita que participa en los inicios del PCN es el P. Carlos Heredia, quien señala que los principales organizadores del Partido son sus amigos D. Francisco Elguero y D. Gabriel Fernández Somellera, a los que él anima, y él mismo consigue de don Porfirio la aprobación de los estatutos del Partido, acción entonces enteramente necesaria. Aunque ya antes los poblanos, con su arzobispo, Ramón Ibarra y González, deseaban formar un partido político. ${ }^{43}$ En realidad, hay que destacar que el nacimiento del Partido fue fruto de los esfuerzos de diversos sectores de la Iglesia, en especial del arzobispo de México, José Mora y del Río, como señala el mismo Heredia. ${ }^{44}$

Desde el inicio de la Revolución, durante la gestión de Madero como presidente, se abre para los jesuitas una situación propicia para la creación y desarrollo de otras organizaciones que tendrán repercusión nacional a nivel social. En 1910, y con motivo de las recientes fiestas del centenario de la Independencia, un grupo de señoras de la capital se pone en contacto con el P. Heredia, que intenta establecer la Escuela Taller de San Felipe de Jesús para niños pobres, y le ofrecen algunos fondos que habían colectado. Heredia aprovecha la relación con ellas y funda, por

${ }^{42}$ Cfr. José Gutiérrez Casillas, S. I., Jesuitas en México durante el siglo XX, p. 77. ${ }^{43}$ Cfr. Marta Eugenia García Ugarte, "Jerarquía católica y laicos durante la Revolución: enfrentamientos, disidencia y exilio político por su colaboración con el huertismo (1910-1914)", p. 237.

${ }^{44}$ AHPM. III, Carlos María de Heredia, S. I., "Carta al R. P. Provincial Marcelo Renaud, S. I.”, Correspondencia, Particulares al Provincial, 1:1912-1922, Heredia Carlos 1913, Orizaba, 30/10/1913, p. 2; AHPM. III, Heredia, "El padre Carlos M. de Heredia, S. I.: Apuntes biográficos", Correspondencia, Difuntos, 21 GU-He, Heredia y de Meca Carlos María de, s. l., ca. julio de 1937, pp. 2-3. 
encargo del arzobispo Mora y del Río, la Asociación de Damas Católicas Mexicanas. ${ }^{45}$

La organización se constituye oficialmente en el mes de agosto de 1911. ${ }^{46}$ Un año después, el 12 de septiembre de 1912, reunidas "más de ochocientas señoras y señoritas de la mejor sociedad", reciben del P. Heredia los lineamientos de la unión: se trata de "una corporación no piadosa sino social que se dedicará [...] a la instrucción religiosa y social del pueblo, de la clase media y también de la clase alta de la sociedad, enseñando a cada uno sus obligaciones [...], entre los obreros, los estudiantes, los maestros y todos aquellos que más influyen en [el] adelanto o retroceso religioso y social de nuestra Patria” ${ }^{47}$ La Unión de Damas Católicas Mexicanas es una organización sociopolítica católica que busca poner sus servicios, su ejemplo y sus donativos en función de la restauración social cristiana. ${ }^{48}$ En abril de 1913, Heredia también establecerá en Guadalajara las Damas Católicas; después de un año tiene 10200 socias. $^{49}$

Heredia funda también la revista mensual El Centro..$^{50}$ Desde el primer número, del 15 de mayo de 1911, aparece su apoyo entusiasta al PCN. Además de organizar otras agrupaciones sociales, hacia 1911, Heredia asume la dirección de la Liga Nacional de Estudiantes Católicos, ayudado por las Damas Católicas. ${ }^{51} \mathrm{La}$

${ }^{45}$ Cfr. ARsi... viII, Heredia "Carta al P. Wernz", México, 31/05/1912, pp. 8-9; Анрм. III, Heredia "Carta al R. P. Provincial Marcelo Renaud, S. I.", cit., 30/Io/I9I3, p. 5; AHPM. II, José Bravo Ugarte, S. I., "Antecedentes y primeros años de la Provincia Restaurada 1816-1913", Noticias de la Provincia, Noticias de la Provincia de México (México), septiembre-octubre 1957, p. 273. Las Noticias de la Provincia son una publicación mensual de cada Provincia jesuítica.

${ }^{46}$ Cfr. Aнpм. III, Heredia "El padre Carlos... Apuntes...", cit., p. 3.

${ }^{47}$ AHPM. III, Heredia "Carta al R. P. Provincial Marcelo Renaud, S. I.", cit., 30/10/1913, pp. 5-6.

${ }^{48}$ Cfr. José Manuel Fernández del Campo, S. I., "¿Qué cosa es la Unión de Damas Católicas?”, pp. 48-53.

${ }^{49}$ Cfr. González Navarro, Cristeros y agraristas, op. cit., p. 247.

${ }^{50}$ Cfr. Arsi... viII, Heredia "Carta al P. Wernz", cit., México, 31/05/1912, p. 1.

${ }^{51}$ Cfr. Decorme, Historia de la... De Madero, op. cit., pp. 278-279 
Liga se había fundado en 1909; los jóvenes "por sí y ante sí habían copiado los estatutos de la Liga de la Juventud Francesa”. ${ }^{52} \mathrm{Y}$ para 1911 tiene ya cerca de once mil asociados por las principales ciudades de la República. Desde que se funda el PCN, la Liga de Estudiantes se integra a sus filas y lo apoya en sus luchas; ${ }^{53}$ es una agrupación de combate. Esta asociación, organizada para los jóvenes preparatorianos, se plantea un proyecto en términos de guerra, con el interés de penetrar y ganar espacios en el terreno del contrincante: "lleva el campo de acción a las mismas trincheras del enemigo", es decir, a las escuelas oficiales que tienen una orientación liberal. ${ }^{54}$

Ese mismo año de 1911, Heredia funda también el Centro de Estudiantes Católicos, en la Ciudad de México. Su lema, que heredará a la ACJM, es "Por Dios y por la Patria". El Centro se forma con elementos del Círculo Filosófico Jaime Balmes y de la Sociedad Científica Francisco Díaz Covarrubias, provenientes de la Escuela Nacional Preparatoria. ${ }^{55} \mathrm{Su}$ objetivo es defender la fe de los estudiantes que están ya en la universidad, y trabajar por alcanzar la libertad religiosa. Heredia relaciona de inmediato a las Damas Católicas con el Centro, para que lo subvencionen económicamente. ${ }^{56}$ En 1912 Heredia también organiza en Guadalajara otro Centro de Estudiantes Católicos. ${ }^{57}$

52 AHPM. III, Heredia "Carta al R. P. Provincial Marcelo Renaud, S. I.", cit., 30/10/1913, p. 4.

${ }^{53}$ Cfr. El Estudiante, Órgano del Centro de Estudiantes Católicos, sept. 1911 y mayo de 1913.

${ }^{54}$ Decorme, Historia de la... De Madero, op. cit., p. 13; Cfr. Gerardo Decorme, S. I., Historia de la Compañia de Jesús, en la República Mexicana durante el siglo XIX, (1880-1914), p. 498.

${ }^{55}$ Cfr. Aнpм. II, Manuel Ocampo, S. I. "La Provincia de México de 1914-1929”, Noticias de la..., Noticias de la..., 1957, op. cit., p. 290.

${ }^{56}$ Cfr. Decorme, Historia de la... De Madero, op. cit., pp. 278-279; АHPM. III, Heredia “Carta al R. P. Provincial Marcelo Renaud, S. I.", cit., 30/10/1913, p. 6. ${ }^{57}$ Cfr. González Navarro, Cristeros y agraristas, op. cit., p. 247. 


\section{LAS ORGANIZACIONES SOCIALES:}

ANTECEDENTES DE UN PARTIDO POLÍTICO CATÓLICO

¿A qué obedece la participación de jesuitas como Bergoënd y otros en la fundación del PCN? Los jesuitas de México se forman en Europa; esto les permite estar en contacto con las nuevas corrientes de pensamiento, como las propuestas católicas en materia de lo social. El punto de inflexión viene a ser la encíclica Rerum Novarum de León XIII (1891). No se puede entender la labor de la Compañía sin tener en cuenta que la doctrina social de la Iglesia en ese momento está enmarcada por esta encíclica; desde aquí, la Provincia Mexicana de la Compañía de Jesús encarna y difunde entre los católicos una militancia con características sociopolíticas. El Papa sostiene que la Iglesia tiene el deber de intervenir en materia social, e invita a una total reconstrucción, restauración de la sociedad..$^{58}$

Esta restauración social significa el restablecimiento de la paz perdida entre las clases antagónicas de la sociedad, especialmente las representantes del capital y del trabajo, ${ }^{59} \mathrm{e}$ invita a todos los obreros católicos a organizarse en sindicatos. ${ }^{60}$ Aunque la difusión de la encíclica al principio es bloqueada por la mayoría de los obispos mexicanos, ${ }^{61}$ más tarde es dada a conocer gracias a una edición anotada que publica Bergoënd, quince años después, en 1906. ${ }^{62}$

${ }^{58}$ Cfr. Joseph B. Gavin, “La enseñanza social católica: 1891-1975”, De la Rerum Novarum al Decreto 4, Promotio Iustitiae 66, (Roma), 3 febrero 1997 p. 3.

${ }^{59}$ Cfr. Manuel Ceballos Ramírez, "La democracia cristiana en el México liberal: un proyecto alternativo (1867-1929)", p. 8; Manuel Ceballos Ramírez, El catolicismo social: un tercero en discordia. Rerum Novarum, la "cuestión social" y la movilización de los católicos (1891-1911), p. 46; Episcopado Mexicano, Pastoral Colectiva sobre la Acción Católica en asuntos sociales, pp. 2-3.

${ }^{60}$ Cfr. León XIII, Rerum Novarum. Encíclica sobre el estado actual de los obreros, núms. 21, 35 y 73 .

${ }^{61}$ La casi totalidad de los obispos la toman con reserva; únicamente dos la publican: el de Guadalajara, Pedro Loza, y el de Yucatán, Crescencio Carrillo. Cfr. Ceballos, El catolicismo social, op. cit., pp. 63-66.

${ }^{62}$ Vid. Bernardo Bergoënd. León XIII y la cuestión social. Encíclica "Rerum Novarum": con divisiones, notas marginales y breves comentarios. 
El pensamiento social de León XIII ofrece a los católicos en México una alternativa ante la situación de crisis nacional con que se había iniciado la última década del siglo xix. Entonces surge una serie de esfuerzos de varios jesuitas, a los que se suman algunos católicos mexicanos, por responder a los problemas sociales planteando soluciones desde la óptica cristiana. ${ }^{63}$

Se puede señalar una primera etapa en estos esfuerzos, algunos anteriores incluso a la Rerum Novarum, que corresponde a las últimas décadas del siglo xIx. Los jesuitas son los pioneros, en 1872 en Puebla, con su Colegio Pío de Artes y Oficios; ${ }^{64}$ es un intento de solucionar la "cuestión obrera" ${ }^{65}$ Organizan luego los Círculos Católicos establecidos en el Distrito Federal (1882), Puebla (1886), Guadalajara y Mérida (1901), y Chihuahua (1904). Representan una ruptura respecto al movimiento católico mexicano anterior; es una corriente que ya se inclina por la participación política. Asumen la devoción al Sagrado Corazón como un símbolo, pero ya con repercusiones sociopolíticas, que desembocará en el culto a Cristo Rey. ${ }^{66}$ Este concepto, que es una noción de poder temporal, responde a una Iglesia que plantea un activismo político: intervenir en la sociedad a través de la formación de partidos católicos.

Otra etapa de mayor trascendencia aparece en la primera década del siglo xx. Es la implementación del catolicismo social, que tiene un claro sentido político, y que promueve, a partir de 1902 y gracias al llamado de Ricardo Sanz de Samper, ${ }^{67}$ los obispos y sacer-

${ }^{63}$ Cfr. Ceballos, El catolicismo social, op. cit., pp. 82-162, passim; Álvaro Matute, "Historiografía del catolicismo social", p. 39.

${ }^{64}$ El Colegio Pío de Artes y Oficios de Puebla se establece en 1872 y dura hasta 1905. Cfr. José Bravo Ugarte, S. I. Historia de México, vol. III: México II: relaciones internacionales, territorio, sociedad y cultura, p. 475.

${ }^{65}$ Cfr. Ceballos, El catolicismo social, op. cit., p. 162.

${ }^{66}$ Cfr. Ibidem, pp. 165-167.

${ }^{67}$ Ricardo Sanz de Samper, prelado representante de León XIII, enviado a México para tratar de establecer una Delegación Apostólica, en 1902. Lo siguieron algunos obispos llamados "obispos sociales", como el arzobispo de México, y los 
dotes mexicanos de diferentes diócesis, formados por los jesuitas de la Universidad Gregoriana ${ }^{68}$ y que habían vivido en el Colegio Pío Latino de Roma, ${ }^{69}$ en particular, el obispo Mora y del Río. ${ }^{70}$

Esta segunda etapa favorece la creación de organizaciones más amplias. Se inicia con la fundación de la Confederación de las Congregaciones Marianas, en 1902. ${ }^{71}$ La primera Congregación, establecida en I87I, fue la de Nuestra Sra. de Guadalupe y San Luis Gonzaga, en la iglesia de Santa Brígida, ${ }^{72}$ en el Distrito Federal. ${ }^{73}$ Después, de 1894 a 1904, se fundan Congregaciones en todas las casas y colegios de la Provincia.

Vienen luego los Congresos Católicos Sociales (1903-1909), en los que toman parte activa los miembros de la Orden. El primero se celebra en Puebla y es preparado por el P. José Mateo Bustos. ${ }^{74}$ El segundo Congreso, celebrado en Morelia en 1904, analiza la cuestión obrera. El tercero es en Guadalajara, en 1906; ahí ya se critica al antiguo régimen y se va asumiendo "lo católico" como identidad y propuesta política. ${ }^{75}$ El cuarto es en Oaxaca en 1909, donde surge la idea de la creación de los Operarios Guadalupanos.

obispos de Guadalajara, Oaxaca, Puebla y Zacatecas, entre otros. Cfr. Francisco Barbosa Guzmán, "La Iglesia en la encrucijada de la Revolución mexicana”.

${ }^{68}$ La Pontificia Universidad Gregoriana, heredera y continuadora del Colegio Romano fundado por san Ignacio de Loyola en 1551, es una Universidad Eclesiástica confiada a la Compañía de Jesús y dedicada prioritariamente a la formación de sacerdotes diocesanos y religiosos de varias órdenes o congregaciones que estudian ahí alguna licenciatura o posgrado.

${ }^{69}$ El Colegio Pontificio Pío Latino Americano se funda en Roma en 1858 con el objetivo de formar candidatos al sacerdocio secular provenientes de América Latina. Desde 1859 la dirección del plantel es confiada a la Compañía de Jesús. ${ }^{70}$ Cfr. Decorme, Historia de la... (1880-1914), op. cit., p. 500.

${ }^{71}$ AHPM. Iv, Rodríguez Jiménez, "Cronología de Fundaciones”, cit., p. 15.

${ }^{72}$ La Residencia Santa Brígida, durante un tiempo Curia Provincial, se abre en la Ciudad de México en 1845 y con sucesivas interrupciones, funciona hasta 1933. Ibidem, pp. 12-18.

73 "Las Congregaciones de San Luis Gonzaga: Apunte Histórico".

${ }^{74}$ Cfr. Ceballos, El catolicismo social, op. cit., pp. 184 y 189.

${ }^{75}$ Cfr. Robert Curley, "Sociólogos peregrinos: teoría social católica en el fin-de-régimen porfiriano”, pp. 200-201. 
En 1908 la Compañía inicia varios Centros Obreros. En Orizaba, el núcleo fabril más grande entonces en la República, con alrededor de 15000 obreros, se abre un centro para oponerse al influjo del Club Liberal de Obreros. ${ }^{76}$ Ahí mismo, se funda la Escuela de San José para Obreros, ${ }^{77}$ que pretende contrarrestar la influencia socialista y masónica. Y en Puebla otro, ${ }^{78}$ que para 1913 cuenta con más de 1500 miembros. ${ }^{79}$

En 1909 surge un cambio de actitud entre varios católicos ante lo político. ${ }^{80}$ Es cuando algunos militantes cristianos proponen ya un proyecto sociopolítico autónomo, el PCN, frente a la crisis final del porfiriato, entre 1909 y 1911, y van a luchar, durante un lustro, de 1909 a 1914, por llevarlo adelante. ${ }^{81}$

\section{La aVentura con Madero}

Con la crisis provocada por el desafío de Madero al sistema político porfiriano, se da lugar al inicio de un proceso de mayor participación ciudadana que representa para los católicos la oportunidad para estructurar el PCN. Pero los problemas del Partido con Madero empiezan muy pronto. El PCN apoya la candidatura de don Francisco a la presidencia de la República, a pesar de que "el Señor Madero declara su hostilidad a los principios del Partido". ${ }^{82}$ En este punto me distancio de Gutiérrez Casillas, porque considero que no interpreta bien sus fuentes al señalar que "nunca

${ }^{76}$ Cfr. Decorme, Historia de la... (1880-1914), op. cit., p. 234.

${ }^{77}$ Esta Escuela de San José para Obreros duró de 1908 a 1914. AHPM. IV, Rodríguez Jiménez, “Cronología de Fundaciones...”, cit., p. I6.

${ }^{78}$ Este Centro Obrero de Puebla pudo subsistir desde 1908 hasta 1914. Cfr. idem. ${ }^{79}$ Cfr. Arsi... Mex. 1003, ix, Fructuoso Gibaja, S. I. "Carta al P. Wernz", 12, Puebla, 09/01/1913, p. 1.

${ }^{80}$ Cfr. Cárdenas Ayala, El Derrumbe: Jalisco, op. cit., pp. 231-242, passim.

${ }^{81}$ Cfr. Ceballos, El catolicismo social, op. cit., p. 49.

82 [Bergoënd], en Gerardo Decorme, S. I., Historia de la Compañia de Jesús: en la República Mexicana. Dispersión y Reorganización: 1914-1924, p. 688.1. 
fueron objetados los principios del partido, que le parecieron bien a Madero" ${ }^{83}$ Además, Madero también exige que sea aceptada la candidatura de José María Pino Suárez para la vicepresidencia, aunque todo el país la rechaza. ${ }^{84} \mathrm{El}$ PCN no apoya esta nominación y en su lugar postula a Francisco de la Barra. ${ }^{85}$

En las elecciones del 15 de octubre de 1911 triunfa Madero. La planilla Madero-Pino Suárez logra el 53 por ciento de los votos. Los norteamericanos otorgan inmediatamente su reconocimiento al nuevo Presidente de México, quien toma posesión el 6 de noviembre de $1911,{ }^{86}$ mas para algunos jesuitas que analizan después los acontecimientos, aun

en las elecciones presidenciales de 1911 hay, como en el tiempo del general Díaz, imposición de candidatos; no de parte del Presidente interino, sino del Apóstol de la Democracia y de su Partido Constitucional Progresista ${ }^{87}$ que, por reprobables medios, impiden el triunfo electoral de Emilio Vázquez Gómez [del Partido Antirreeleccionista, ${ }^{88}$ para la vicepresidencia], de Bernardo Reyes [del Partido Reyista] ${ }_{,}^{89}$ o de Francisco León De la Barra [del Partido Católico, también para la vicepresidencia]..$^{90}$

${ }^{83}$ Cfr. Gutiérrez Casillas, Jesuitas, op. cit., p. 20.

${ }^{84}$ Cfr. Decorme, Historia de la... Dispersión, op. cit., p. 688.3.

${ }^{85}$ Cfr. Alfonso Junco, Un siglo de Méjico [sic]: de Hidalgo a Carranza, p. 264.

${ }^{86}$ Cfr. Womack, "La Revolución mexicana", op. cit., p. 153.

${ }^{87} \mathrm{El}$ Partido Constitucional Progresista fue fundado por Gustavo Madero el 9 de julio de 1911, después de declarar que el Partido Nacional Antirreeleccionista no tenía ya razón de ser. Cfr. Bravo Ugarte, Compendio de historia, op. cit., p. 264. ${ }^{88}$ El Partido Antirreeleccionista fue establecido por Madero en mayo de 1909. Defendía la no reelección, la estricta observancia de la Constitución, la efectividad del sufragio, la libertad municipal y el respeto a las garantías individuales. Cfr. José Bravo Ugarte, Historia de México. México I: Independencia, caracterización politica e integración social, p. 425.

${ }^{89}$ El Partido Reyista estaba dirigido por Samuel Espinosa de los Monteros y proclamaba al general Reyes como "el hombre único" para asumir el poder. $C f$ r. idem.

${ }^{90}$ Gutiérrez Casillas, Jesuitas, op. cit., p. 18. 
Esto nos hace pensar que Madero, más allá de sus principios, cayó en el juego de la política no democrática. ${ }^{91}$ Además, si el Madero revolucionario arrastró a multitudes, la popularidad va disminuyendo para el Madero ya gobernante. El problema aparece sobre todo cuando, por los compromisos de clase de los maderistas, las vagas promesas de reforma social contenidas en el Plan de San Luis, sobre todo la del reparto agrario, se van postergando hasta desembocar en la insubordinación del zapatismo. ${ }^{92}$

Por otra parte, para el PCN siguen los problemas; el 30 de junio de 1912 el Presidente, por su inclinación a favorecer al grupo anticlerical de su hermano Gustavo A. Madero, tiene la debilidad de tolerar que sean ilegal y atentatoriamente desechadas las credenciales de la mayor parte de los diputados católicos. ${ }^{93}$ Esto manifiesta que el "laboratorio democrático" que se genera con el Estado maderista también lleva consigo nuevas formas de manipulación del voto. Aquí aparece el anticlericalismo de Estado que abrazarán los gobiernos de la Revolución. Y Madero no estuvo ajeno a estas manipulaciones. ${ }^{94}$

Sin embargo, a partir de estas elecciones se puede medir el desarrollo e influjo que el PCN ha adquirido. Logra ganar varias curules en las Cámaras, gracias a la educación electoral y a la creación de la identidad partidista que ofrece a sus miembros. ${ }^{95} \mathrm{El}$ partido presenta cinco candidatos para la Suprema Corte, 19 para el Senado y 193 para la Cámara de Diputados; de éstos consigue sacar adelante sólo a cuatro senadores y a 29 diputados pertene-

${ }^{91}$ Cfr. Bravo Ugarte, Historia de México..., I, op. cit., pp. 426-427.

${ }^{92}$ Otro conflicto surge con el Plan de la Empacadora, de Pascual Orozco, porque Madero declara inválida la candidatura de aquél para ser gobernador de Chihuahua. La rebelión orozquista estalla el 3 de marzo de 1912. Madero envía a Victoriano Huerta a aplacar la revuelta, que es derrotada el 7 de julio del mismo año. ${ }^{93}$ Aquí el autor del "Apéndice III ${ }^{\mathrm{a}}$ ", Bergoënd, se refiere a las elecciones federales para el Congreso. [Bergoënd], en Decorme, Historia de la... Dispersión, op. cit., p. 688.3 .

${ }^{94}$ Cfr. Cárdenas Ayala, El Derrumbe: Jalisco, op. cit., pp. 416-424.

${ }^{95}$ Cfr. Ibidem, p. 401. 
cientes a la XXvi Legislatura, ${ }^{96}$ que inicia el 12 de septiembre de 1912. Los estados de mayor representación católica en el Congreso son: Guanajuato, Jalisco, México, Michoacán y Zacatecas. Los diputados del PCN tratan de conjurar la Revolución por medio de una legislación avanzada, tanto en el campo político como en el social. ${ }^{97}$ Aunque no haya logrado sobrepasar a otros partidos, su posición le permite ser el fiel de la balanza, pues los escaños ganados en ambas Cámaras son suficientes para formar una mayoría con los científicos, e incluso con los reyistas.

El PCN crece rápidamente; hacia los años de 1912-1913 llega a tener 485856 militantes; ${ }^{98}$ lo que le coloca a la vanguardia de la organización partidista en México. ${ }^{99}$ Habría que valorar este dato, teniendo en cuenta que la población total del país, en 1912, es de alrededor de 13 millones y medio de habitantes; y quitando mujeres y niños, queda una población electoral total de un poco menos de tres millones y medio de electores ${ }^{100}$ (y eso sin tener en cuenta que muchos se abstienen de votar); de los cuales, cerca de medio millón son del PCN. Pero no tardan en reaccionar en contra del PCN los miembros del Partido Liberal. ${ }^{101}$ La consolidación del PCN provoca entonces la radicalización del anticlericalismo.

${ }^{96}$ Cfr. Junco, Un siglo de México, op. cit., p. 264.

${ }^{97}$ Cfr. Cárdenas Ayala, El Derrumbe: Jalisco, op. cit., p. 394.

${ }^{98}$ Cfr. Bravo Ugarte, Historia de México..., I, op. cit., p. 428; Ceballos, El catolicismo social, op. cit., p. 402.

${ }^{99}$ Cfr. Matute, "Historiografía del catolicismo", op. cit., p. 41.

${ }^{100}$ Inegi. Censos de Población y Vivienda, 1895 a 2010, Resumen del censo general.

${ }^{101}$ El Partido Liberal o Partido del Progreso fue un partido político mexicano fundado a principios del siglo xIx y en el que participaron personajes como José María Luis Mora, Benito Juárez y Porfirio Díaz. Los liberales pretendían separar la Iglesia del Estado; despojar a la Iglesia de los bienes que tenía, así como quitarle los tributos, los registros civiles, los fueros, anular los votos religiosos y dejarla sin el control de la educación. En este momento estaba constituido por los antiguos porfiristas. Cfr. Cárdenas Ayala, El Derrumbe: Jalisco, op. cit., p. 399. Pero hay que seńalar que, en 1912, no se puede considerar que el conjunto de fuerzas liberales que existen sea un bloque, sino más bien un abanico de posturas; lo que nos obliga a tener que matizar cualquier afirmación respecto a ellos. 
En Guadalajara se crea una fuerte tensión entre los liberales-conservadores ${ }^{102}$ y el PCN; esto muestra la lucha por el poder que está sucediendo. ${ }^{103}$ Los ataques contra el PCN se dirigen justo hacia el colegio de los jesuitas, el Instituto de San José, y contra su rector, el P. Manuel Díaz Rayón, diciendo que él es el alma del partido; "lo que es absolutamente falso", según escribe el Provincial al Asistente de España. ${ }^{104}$ Lo que sí consta es que varios exalumnos del colegio, que ahora estudian en la universidad, militan de modo activo en el PCN; ${ }^{105}$ y, desde 1911, el director de la Sociedad de Antiguos Alumnos del Instituto de San José, es Bergoënd. ${ }^{106}$ Una estrategia de los jesuitas, entonces, es conseguir influencia en la estructura política a través de estas sociedades de exalumnos establecidas en cada colegio de la Compañía. Con esto podemos inferir que los jesuitas influyeron, aunque de manera indirecta, en las elecciones de 1912.

Alfredo Méndez Medina, S. I., y el problema social

En el trabajo social-político destaca el P. Alfredo Méndez Medina, quien regresa a México el 11 de diciembre de 1912,107 después de estar seis ańos estudiando en Lovaina, Bélgica. ${ }^{108}$ En enero de 1913, un mes antes del derrocamiento de Madero, Bergoënd y

${ }^{102}$ Antigua elite política porfiriana, interesados en que siguiera el statu quo; varios anticlericales a ultranza forman parte de ella.

${ }^{103}$ Cfr. Cárdenas Ayala, El Derrumbe: Jalisco, op. cit., p. 373.

${ }^{104}$ ARsi... VIII, Ipiña, "Carta al P. Isidoro Zameza...”, 19, México, 13/05/1912, pp. 1-2.

${ }^{105}$ Cfr. Aнpm. II, Noticias de la..., Noticias Edificantes de la Provincia de México, 1909-1913, núm. 15, El Llano: Colegio de San Estanislao, enero 1912, p. 2.

${ }^{106}$ Cfr. Ríus Facius, Bernardo Bergoend [sic], S. J., op. cit., p. 25.

${ }^{107}$ Emeterio Valverde Téllez, Bio- bibliografía eclesiástica mexicana, León 1913, pp. 279-285.

${ }^{108}$ AHPM. III, Méndez Medina, Alfredo, S. I., "Carta al R. P. Marcelo Renaud", Correspondencia, Particulares al Provincial, 1, 1912-1922, 1912-1914, México, $12 / 12 / 1913$, p. 2. 
Méndez Medina asisten como asesores ${ }^{109}$ a la segunda Dieta de la Confederación Nacional de los Círculos Católicos de Obreros, respaldada por el episcopado mexicano, en Zamora. ${ }^{110}$ En ella, Méndez Medina propone la sindicalización como la forma más apropiada de agremiación católica, ${ }^{111}$ varios años antes de que existiera la CROM. También apoya una reforma sobre la propiedad de la tierra, aunque gradual, al defender para el pueblo un "bien de familia”, un patrimonio inembargable e indivisible, una pequeña finca rural. ${ }^{112}$ Esta propuesta aparece muy temprano, en 1913; Lázaro Cárdenas no llevará a cabo la reforma agraria sino hasta 1934.

\section{Los Jesuitas y Madero}

Pero, efectivamente, ¿cómo había sido la relación de los jesuitas con Madero? ¿Hasta dónde se puede afirmar que conspiraron contra él, y que así se explica la agresividad antijesuítica del carrancismo, que se decía querer reivindicar a Madero?

Madero es alumno de los jesuitas en el colegio de Saltillo y miembro de la Congregación Mariana. Está ahí hasta 1886, ${ }^{113}$ después de cursar la primaria. Ya adulto manifiesta tener un espíritu iluso y bondadoso, pero cae en las redes del espiritismo. ${ }^{114}$ Una vez iniciada, la Revolución maderista es bien recibida por la Compañía, porque "auguraba una era de libertad política y religiosa en que entraron con entusiasmo todos los católicos mi-

${ }^{109}$ Cfr. анрм. II, Noticias de la..., Noticias Edificantes de..., op. cit., núm. 20 a. 4, núm. 1, El Llano: Colegio de San Estanislao, 12/02/1913, p. 1.

${ }^{110}$ Realizada del 19 al 22 de enero de 1913. Trató sobre la postura de la Iglesia respecto a la organización de la clase obrera. Cfr. AHPM. III, Méndez Medina, “Carta al R. P. Marcelo Renaud”, cit., México, 12/12/1913, pp. 1-2.

${ }^{111}$ Ibidem, pp. 1r-2.

${ }^{112}$ Cfr. González Navarro, Cristeros y agraristas, op. cit., pp. 241-242.

${ }^{113}$ Cfr. Aнpm. IV, 369, "Proclamación de Dignidades", Colegio de San Juan Nepomuceno, Récord (1885-1893), 18/03/1886, pp. 19, 25 y 31. ${ }^{114}$ Cfr. Gutiérrez Casillas, Jesuitas... siglo XX, op. cit., p. 77. 
litantes (obispos, clero y jesuitas)". ${ }^{115}$ Esta caracterización ya nos indica la postura que van a asumir muchos miembros de la Orden durante la lucha armada. Así, a los lados del maderismo, los jesuitas surgen como nuevos actores que, junto con otros, al ser trasmutados por los acontecimientos, permanecen y fructifican en el universo político del país. ${ }^{116}$

Las relaciones entre los jesuitas y Madero, ya presidente, inicialmente son de colaboración. A fines de diciembre de 1911, Madero pide al provincial Ipiña que envíe algunos misioneros para pacificar a los yaquis y reparar las injusticias que con ellos había cometido el antiguo régimen. El Provincial manda al P. Manuel Piñán a Hermosillo. ${ }^{117}$ Madero, luego, devuelve a los jesuitas el antiguo colegio de Tepotzotlán, que le piden para formar ahí misioneros para El Yaqui. ${ }^{118}$

\section{EL DESENCANTO: IMPLICACIÓN DE LOS JESUITAS \\ EN LA MUERTE DE MADERo}

Pero las cosas no sucedieron como los jesuitas habían esperado con Madero. "Los decepcionó; era de muy buena voluntad, pero de pocas luces, no discernía tanto; y se dejó arrastrar por sus familiares que no tenían tan puras intenciones como él". ${ }^{119} \mathrm{Y}$ los jesuitas se van desilusionando porque el deterioro del régimen

${ }^{115}$ Decorme, Historia de la... De Madero, op. cit., p. 1.

${ }^{116}$ Cfr. Rodríguez Kuri, Historia del desasosiego, op. cit., p. 87.

${ }^{117}$ La misión de El Yaqui, en Sonora, se reabre en 1912 y permanecerá hasta 1913. Aнpm. IV, Rodríguez Jiménez, Cronología de Fundaciones..., cit., p. I7; Cfr. Aнpм. II, Noticias de la..., Noticias Edificantes de..., op. cit., núm. 15, cit., El Llano: Colegio de San Estanislao, enero 1912 p. 2.

${ }^{118}$ Cfr. Gul..., H. Román Sanjuán, "Entrada de los Carrancistas en Tepotzotlán: Del Diario del H. San Juan [sic], S. J.”, 63, 11, Varia-Richard H. Tierney Papers (1914-1919), s/n, s. l., s. f. [1914], p. 1.

${ }^{119}$ Aнрм. 0, Rafael Ignacio Rodríguez Jiménez, "Entrevista a Javier Cacho Vázquez, S. I.”, Caja 2, folder 81-85, México, D. F., 20/06/2007. 
significa el fin de una esperanza de cambio social. ${ }^{120}$ Varios de los que conspiran contra él se ponen en contacto con algunos miembros del PCN, en enero de 1913. Éstos piden orientación a los obispos Mora y del Río, Eulogio Gillow, José Otón Núñez y Emeterio Valverde, que están reunidos en la Dieta de Zamora, junto con Bergoënd y Méndez Medina. La respuesta unánime es "que era ilícita la rebelión contra el legítimo gobernante, y que por ningún motivo podrían los católicos, [...] participar en conspiración alguna". ${ }^{121}$

No obstante, después Villa llega incluso hasta a inculpar a los jesuitas de algo muy grave: de que habían colaborado con Huerta para mandar matar a Madero; esto dará pie para la supuesta reivindicación carrancista contra la Compañía. El P. José Méndez, uno de los que van a ser expulsados del colegio de Saltillo por Villa, sostiene que éste les grita antes de torturarlos: "Ustedes le ayudaron a Huerta, con su dinero, a matar a Panchito Madero". ${ }^{122}$ La base de estas acusaciones no ha sido comprobada por la historiografía. Además, existe otro dato importante al respecto: se acusa a Mora y del Río de haber financiado el golpe contra Madero; lo grave es que lo dice el delegado apostólico, Tomasso Boggiani, en su informe de 1914 al Vaticano. ${ }^{123}$

Por lo demás, el interés de aparecer como el vengador de Madero, por parte de Carranza, fue un mero pretexto para desplegar los ataques contra los católicos; y, consecuentemente, contra los jesuitas. En realidad había un conflicto entre los dos líderes: "don Venustiano y don Francisco estaban en pésimas relaciones; [...] ya en las postrimerías del régimen [...] la animadversión era in-

${ }^{120}$ Cfr. Cárdenas Ayala, El Derrumbe: Jalisco, op. cit., pp. 425-430.

${ }^{121}$ Junco, Un siglo de México, op. cit., p. 265.

${ }^{122}$ Narración del P. José Méndez, S. I., en Decorme, Historia de la... De Madero, op. cit., p. 37.

${ }^{123}$ Cfr. Archivo Secreto Vaticano (Asv), Rapporto finale di Mons. T. Boggiani Del. Apco. al Messico, negli anni 1912-1913, Busta núm. 27, Fasc. 88, ff. 118-116. Apud García Ugarte, "Jerarquía católica”, op. cit., pp. 250 y 259.

Un proyecto jesuita a favor de la democracia / |2| 
dudable". ${ }^{124}$ Un "importante colaborador" de Madero asegura incluso que Carranza intentaba conspirar contra Madero. ${ }^{125}$ En conclusión, creo que, como todo en la historia, la relación y problemática de Madero con Carranza es multifactorial.

\section{UNA ALTERNATIVA POLÍTICA NO PARTIDISTA: LA ACJM}

Bergoënd intuye que hay que preparar a los jóvenes para que intervengan en la configuración de los destinos de la Patria. Para eso necesita organizar una asociación que se proponga cooperar a la restauración del orden social cristiano. Se basa en la Asociación Católica de la Juventud Francesa. ${ }^{126}$ Es posible que Bergoënd considere que, en ese momento, la opción política partidista ya no es prioritaria; por eso, en noviembre de 1912, prefiere retirarse de la asesoría al PCN. ${ }^{127}$ Se puede conjeturar que deja el partido porque en su seno empiezan a surgir posturas con las que no está de acuerdo.

El 9 de marzo de 1913 Bergoënd sustituye a Heredia en la asesoría de la Liga de Estudiantes Católicos y del Centro de Estudiantes Católicos y les propone la creación de la Asociación Católica de la Juventud Mexicana (АСJM). ${ }^{128}$ Esta asociación trabajaría, primero, en el campo de la acción cívica, para después influir en decisiones orientadas en favor de la Iglesia y del país, actuando en la vida política de la nación. La asociación se va a dedicar a la "acción social": ayuda a la estabilidad de la familia, apoya a los

${ }^{124}$ Junco, Un siglo de México, op. cit., p. 267.

${ }^{125}$ Ibidem, pp. 267-268. El autor no nos dice quién es ese "importante colaborador" de Madero.

${ }^{126}$ Relación del mismo Bergoënd en el Primer Consejo Federal de la ACJM.

${ }^{127}$ Cfr. AJGC... Archivo Miguel Palomar y Vizcarra. Correspondencia, "Carta de P. Bergoënd a Miguel Palomar y Vizcarra”, archivo 3, 29/11/1912.

${ }^{128}$ Cfr. María Luisa Aspe Armella, La formación social y politica de los católicos mexicanos: la Acción Católica Mexicana y la Unión Nacional de Estudiantes Católicos, 1929-1958, p. 65.

I 22 / Rafael Ignacio Rodríguez Jiménez 
obreros desde el sindicalismo católico, y busca la legislación más adecuada para la protección de los débiles. La ACJM es producto de las inquietudes organizativas derivadas de las enseńanzas de León XIII, encaminadas por igual a lo social que a lo político.

La ACJM se funda en agosto de 1913, durante el Segundo Congreso Mariano Nacional, por la unión de la Liga Nacional de Estudiantes Católicos con las Congregaciones Marianas; ${ }^{129}$ el 20 de octubre de 1913 se integra también el Centro de Estudiantes. ${ }^{130}$ Tanto el lema "Por Dios y por la Patria", como la práctica que realiza, nos dejan ver que la ACJM tiene, desde sus orígenes, una orientación política y social. ${ }^{131}$

Victoriano Huerta tolera la fundación de esta nueva organización "religiosa". ${ }^{132}$ Esta asociación poco a poco va a ir llenando una larga historia de acción política respaldada por la Iglesia, incluyendo manifestaciones no violentas, como el apoyo al homenaje a Cristo Rey, y boicots de protesta por las leyes anticlericales. ${ }^{133}$ Bergoënd "cultivó [...] a los jefes que más tarde acaudillaron la defensa de Dios y de la Patria", ${ }^{134}$ en la Guerra cristera. El Arzobispo de México declarará después que la АCJM fue, durante la Revolución, la principal defensora de la Iglesia. ${ }^{135}$ Ésta es la primera АСјм, la original (1913-1929), que se caracteriza por su radicalidad y heroísmo durante la Guerra de los cristeros; después surgirá otra АCJM, la institucional (1929-1935), cuando la jerarquía la sujete a los obispos. ${ }^{136}$

${ }^{129}$ Cfr. Gutiérrez Casillas, Jesuitas... siglo XX, op. cit., p. 108.

${ }^{130}$ Cfr. Decorme, Historia de la... De Madero, op. cit., p. 280.

${ }^{131}$ Cfr. Peter Lester Reich, "Mexico's Hidden Revolution: The Catholic Church in Politics Since 1929", p. 54.

${ }^{132}$ Cfr. Womack, "La Revolución mexicana”, op. cit., p. 166.

${ }^{133}$ Cfr. Matute, "Historiografía del catolicismo", op. cit., p. 43; Reich, Mexico's Hidden Revolution, op. cit., p. 54.

${ }^{134}$ Ríus Facius, Bernardo Bergoend, [sic] S. J., op. cit., p. 38.

${ }^{135}$ Cfr. "Informe presentado por la ACJM en el Congreso Internacional de la Juventud Católica en Roma: Septiembre, 1921”, p. 46.

${ }^{136}$ Cfr. Imelda Baca Prieto, "La intelectualidad estudiantil a principios del siglo xx. El caso de la Unión Nacional de Estudiantes Católicos”, pp. 77-78. 
Un mes después del asesinato de Madero, hacia marzo de 1913, Méndez Medina organiza tres Círculos de Estudios Sociales en la capital. ${ }^{137}$ El primero es el Centro León XIII, ${ }^{138}$ para la elaboración de leyes laborales. Después establece otro, con preceptores de algunos Círculos Católicos de la Confederación Obrera, ${ }^{139}$ para organizar a los obreros sindicalmente. Y el tercero está destinado a profesionistas y comerciantes..$^{140}$

En la lucha de poder que se va dando entre los grupos organizados por la Compañía y los de los liberales, ${ }^{141}$ una prioridad de los Círculos de Estudios es proponer al Congreso de la Unión leyes sociales. ${ }^{142}$ Pero algunas, como la del Bien de Familia y la de las Uniones Profesionales, ${ }^{143}$ sólo logran ser aprobadas en el Congreso local de Guadalajara. ${ }^{144}$

En cuanto a los sindicatos, el primero que Méndez Medina establece es el de Artes Constructivas, para albańiles y canteros en la capital del país. Plantea entonces cambiar de estrategia frente al problema social: pasar de los Círculos Católicos de Obreros a los sindicatos católicos, y contrarrestar así el sindicalismo socialista. ${ }^{145}$ A pesar de los estragos de la Revolución, llega a agrupar más de

${ }^{137}$ Cfr. Decorme, Historia de la... (1880-1914), op. cit., p. 501.

${ }^{138}$ Cfr. Aнpm. IV, 385, "Litterae Annuae Collegii Mexicopolitani Sancti Francisci Borgiae...1913”, p/u.

${ }^{139}$ Cfr. Aнрм. III, Méndez Medina "Carta al R. P. Marcelo Renaud”, cit., 12/12/1913, pp. 2r-3.

${ }^{140}$ Cfr. Анрм. II, Noticias Edificantes de..., op. cit., núm. 22, a. 4, núm. 3, Noticias de la..., El Llano: Colegio de San Estanislao, 15/06/1913, p. 4.

${ }^{141}$ Cfr. Decorme, Historia de la... De Madero, op. cit., pp. 14-15.

${ }^{142}$ AHPM. IV, 385, "Historia Collegii Sancti Francisci Borgiae... 1913", cit., Anexo.

${ }^{143}$ Cfr. AGN. III, José Mora y del Río et al., "Carta al Señor General don Álvaro Obregón, Presidente de la República Mexicana”, Grupo 182: Obregón-Calles, Expediente: 438-c-4 (viII), Legajo: S I, México, 05/02/1923, p. 3r.

${ }^{144}$ Cfr. Decorme, Historia de la... De Madero, op. cit., p. 399.

${ }^{145}$ Cfr. Aнpм. III, Méndez Medina "Carta al R.P. Marcelo Renaud", cit, 12/12/1913, pp. 4r-5. 
30 ooo obreros. Su obra progresa y va a durar hasta 1924 , cuando la СRОм corporativizará a todos los obreros del país. ${ }^{146}$

Sobre la intervención de los jesuitas en el campo social, el padre General Wernz, en marzo de 1913, puntualiza: “está bien que promuevan obras sociales eficazmente, pero procuren no intervenir en su administración temporal, ni en cuestiones políticas"; prefiere que más bien ayuden a pobres y obreros desde el terreno espiritual. ${ }^{147}$ Esto manifiesta una advertencia, aunque velada, sobre la asesoría de algunos jesuitas al PCN, y la dirección de organizaciones sociopolíticas como la ACJM. Además, la documentación muestra una tensión entre lo social y lo político; es difícil señalar una línea divisoria entre los dos ámbitos. Queda ambigua a partir, precisamente, del impulso de la Rerum Novarum. La dimensión política muchas veces queda oculta detrás de la "acción social". ${ }^{148}$

\section{Conclusiones}

Para cerrar este artículo, podemos subrayar que el inicio de la Revolución sorprende a los jesuitas. Al principio, los miembros de la Compañía no dan mucha importancia a los acontecimientos del comienzo del conflicto; pero, en cuanto los maderistas crean problemas en el templo jesuita de Parras, el padre Provincial se preocupa tanto porque se pueda recrudecer la lucha, como porque Estados Unidos pueda invadir el país.

Aunque el fenómeno revolucionario no aparece como algo sorpresivo para todos los miembros de la Orden: en el contexto de la primera década del siglo xx, ya hay un proyecto político y social de algunos jesuitas, previo a la Revolución; y, a pesar de que se verá

${ }^{146}$ Cfr. Aнpm. IV, 385, "Historia Collegii Sancti Francisci Borgiae... 1913", cit., p. 3; Decorme, Historia de la... (1880-1914), op. cit., p. 501.

${ }^{147}$ ARsi... Epistolae Praepositi Generalis..., cit., Wernz, "Carta al R. P. Fructuoso Gibaja”, Romae, 26/03/1913, p. 62.

${ }^{148}$ Cfr. Cárdenas Ayala, El Derrumbe: Jalisco, op. cit., p. 232. 
afectado por ésta, lucharán por llevarlo adelante durante varios años. Las figuras emblemáticas que empiezan a destacar por su actividad sociopolítica son los padres Bergoënd, Heredia y Méndez Medina. Estos personajes sintetizan la actividad de otros miembros de la Orden que, no obstante que no aparecen o aparecen poco, simpatizan y apoyan la causa. Como árbitro o ejecutor central entre los jesuitas aparece el padre Provincial, en este momento el P. Ipińa. El hilo conductor de la narración son los "Apuntes" y el libro inédito de Decorme, que recogen muchas cartas con información de autores ahora desconocidos para nosotros, pues se perdieron con la Revolución. Como ejemplo, podríamos señalar la correspondencia de varios jesuitas, "cartas y autógrafos que han llegado a nuestras manos, algunos de los cuales existen aún en el archivo"; ;49 pero la mayoría ha desaparecido. Principalmente las cartas anuas e historias de cada casa o colegio de la Provincia. ${ }^{150}$

A raíz del movimiento internacional producido por la Rerum Novarum respecto a la acción social católica, y del contexto nacional caracterizado por la "paz porfiriana", algunos jesuitas organizan y asesoran grupos que puedan participar en política con el fin de modificar la Constitución, lo que tiene como consecuencia la formación del Partido Católico Nacional; y así, varios militantes católicos pasan de la acción social a la acción política, asesorados por jesuitas.

En 1913 los jesuitas quieren para el país un cambio político democrático y legal, a través del PCN; pero, a causa de las divisiones ideológicas que surgen en el Partido, Bergoënd prefiere dejar la asesoría del éste y forma una organización sociopolítica de jóvenes, la АСЈM, que tendrá impacto a nivel nacional.

Los jesuitas aprovechan así el espacio que les deja Huerta para formar grupos de militantes e impulsar las actividades sociopolí-

\footnotetext{
${ }^{149}$ Decorme, Historia de la... Dispersión, op. cit., p. IX

${ }^{150}$ Cuando he logrado identificar las fuentes originales, hago la referencia a ellas; cuando no, dejo sólo la cita del texto inédito de Decorme.
} 
ticas. En este momento no hay una clara línea divisoria entre el trabajo social y el político. Empiezan a florecer los Círculos de Estudios que promueven leyes en beneficio de los trabajadores, y se desarrollan los sindicatos organizados por Méndez Medina. La Compañía establece desde todos sus frentes, teniendo en cuenta la orientación propia de cada institución, programas para la solución de la cuestión social, en un contexto de lucha por ganar áreas de influencia frente a la labor de los liberales.

A lo largo de este recorrido, he mostrado cómo los jesuitas estaban implicados políticamente, durante la primera etapa de la Revolución, con un proyecto de carácter democrático, a través de las instituciones que impulsaron para organizar la participación de muchos militantes católicos, en particular por su intervención en la formación del PCN. Esta postura contrasta con la posición que asume la mayoría del clero, que prefiere mantenerse en una actitud pasiva ante la orientación anticlerical que va tomando la Revolución maderista. También, he analizado cómo este proyecto jesuita chocó con Madero y, sobre todo, con los grupos anticlericales liderados por su hermano Gustavo. Por último, he expuesto la manera en que, después del fusilamiento del "apóstol de la democracia”, los miembros de la Orden prefieren, en este nuevo contexto, privilegiar las organizaciones sociopolíticas no partidistas como la АCJM, los Círculos de Estudios Sociales y los Sindicatos Católicos, con el propósito de cooperar así con la restauración del orden social cristiano.

Con el abordaje que he realizado, doy cuenta de cómo la Compañía de Jesús actuó a distintos niveles para vivificar las “asociaciones intermedias", y del modo particular en el que se puso en práctica el catolicismo social en México, a partir de los principios de la democracia cristiana expuestos en la encíclica Rerum Novarum. Esto se llevó a cabo a través de organizaciones sociopolíticas impulsadas por la Compañía a lo largo de todo el país.

Aunque, finalmente, Decorme advierte que, para la Provincia mexicana, el año de 1913 y la mitad de 1914 son "como un Do- 
mingo de Ramos, seguido de las más trágicas semanas”, ${ }^{151}$ pues la mayoría de estas iniciativas va a terminar ahogada por los embates de Huerta y luego por la Revolución carrancista, a partir de la expulsión y salida de los jesuitas del país en 1914. Sin embargo, va a persistir, junto con algunas Congregaciones Marianas, una institución que servirá de puente hasta el retorno de la Compañía y que será la base para el nuevo desarrollo de las obras sociopolíticas: la ACJM. 底

\section{Fuentes}

\section{Archivos consultados}

AGN: Archivo General de la Nación.

Los documentos consultados se encuentran en las Galerías in y v, Sección de Documentación de la Administración Pública (1910-1988); según Grupos y Series correspondientes.

AHpM: Archivo Histórico de la Provincia Mexicana de la Compañía de Jesús.

Los documentos consultados se encuentran en la Sección 0: Entrevistas de Investigación, Sección I: Fondos Documentales, Sección II: Historia de la Provincia de México, Sección iII: Archivo Antiguo del Padre Provincial, Sección rv: Historia de las Casas, Sección v: Historia de Asuntos Particulares, Sección vi: Vida de Jesuitas de la Provincia Mexicana, Sección vir: Publicaciones Periódicas, o Sección viri: Escritos de jesuitas de la Provincia; según los Grupos y Series correspondientes.

AJGC: Archivo Jesuita de la Guerra cristera en el iteso.

Archivo Miguel Palomar y Vizcarra. Correspondencia.

ARSI: Archivum Romanum Societatis Iesu.

Los documentos consultados se encuentran en la División Nuova Compagnia, Sección I: Epistolae Provincia Mexicana; según los Grupos y Fascículos correspondientes. Las traducciones son mías.

GUL: Georgetown University Library.

Los documentos consultados se encuentran en la División Special Collections; según las Secciones, Subsecciones y Grupos correspondientes. Las traducciones son mías.

${ }^{151}$ Decorme, Historia de la... De Madero, op. cit., p. 5. 


\section{Bibliografia}

Aspe Armella, María Luisa. La formación social y política de los católicos mexicanos: la Acción Católica Mexicana y la Unión Nacional de Estudiantes Católicos, 1929-1958, México, Universidad Iberoamericana, 2008.

Barquín y Ruiz, Andrés. Bernardo Bergöend, [sic] S. J., México, Jus, 1968 (México Heroico).

Bergoënd, Bernardo. León XIII y la cuestión social. Encíclica "Rerum Novarum": con divisiones, notas marginales y breves comentarios, $2 \mathrm{a}$. ed., México, Asociación Católica de la Juventud Mexicana, 1924 (1906), (Círculos de Estudios. Serie B. Estudios Sociales Núm. 1).

Bravo Ugarte, José. Compendio de historia de México: hasta 1964, 10a. ed., México, Jus, 1968 (1946).

- Historia de México. México I: Independencia, caracterización politica e integración social, 3a. ed., México, Jus, 1962 (1944), t. 3.

. Historia de México. México II: relaciones internacionales, territorio, sociedad y cultura, México, Jus, 1959, t. 3.

Cárdenas Ayala, Elisa. El Derrumbe: Jalisco, microcosmos de la revolución mexicana, México, Tusquets, 2010 (Historia Colección Centenarios).

Ceballos Ramírez, Manuel. "Conservadores e intransigentes en la época de Porfirio Díaz”, en Renée de la Torre, Marta Eugenia García Ugarte y Juan Manuel Ramírez Sáiz (comps.), Los rostros del conservadurismo mexicano, México, CIESAS, 2005, pp. 123-137.

. El catolicismo social: un tercero en discordia. Rerum Novarum, la "cuestión social" y la movilización de los católicos (1891-1911), México, El Colegio de México, 1991.

- "La democracia cristiana en el México liberal: un proyecto alternativo (1867-1929)", México, Imdosoc, 1987.

. "Los Operarios Guadalupanos: intelectuales del catolicismo social mexicano 1909-1914”, en Manuel Ceballos Ramírez (coord.), Catolicismo social en México. Las instituciones, México, Imdosoc, 2005. t. II, pp. 57-103.

Certeau, Michel de. La escritura de la historia, tr. Jorge López Moctezuma, México, UIA, 1985 (1978) [L'écriture de l'histoire, París, Gallimard].

Curley, Robert. "Sociólogos peregrinos: teoría social católica en el fin-de-régimen porfiriano", en Manuel Ceballos Ramírez y Alejandro Garza Rangel (coords.), Catolicismo social en México: teoría, fuentes e historiografia, Monterrey, Academia de Investigación Humanística, 2000, t. 1, pp. 195-237. 
Decorme, Gerardo [obras inéditas]

Historia de la Compañia de Jesús: en la República Mexicana. Dispersión y reorganización: 1914-1924 [Apuntes], Original Ms. tip. AHPM, viII, Decorme, Historia Decorme 6 y 6 bis, Socorro, Texas, Primera copia de 1931 (1927) t. 4. s/p.

. Historia de la Compañia de Jesús: en la República Mexicana. De Madero a Calles 5 oct. 1910 - 1 diciembre 1924: dispersión y reorganización, Ms. tip. AHPM, VIII, Decorme, Historia Decorme, 15 y 15 bis. Socorro, Texas. Original corregido en 1953. Continuación de Historia de la Compañia de Jesús: en la República Mexicana durante el siglo XIX, Guadalajara, s.p.i., 1914 y 1921.

[Obras publicadas]

- Historia de la Compañía de Jesús, en la República Mexicana durante el siglo XIX, (1880-1914), Chihuahua, Ediciones Canisio, 1959, t. 3, 506 pp.

Episcopado Mexicano. Pastoral Colectiva sobre la Acción Católica en asuntos sociales, 08/10/1923. Tlalpam [sic], Imprenta A. Patricio Sanz, 1923.

García Ugarte, Marta Eugenia. “Jerarquía católica y laicos durante la Revolución: enfrentamientos, disidencia y exilio político por su colaboración con el huertismo (1910-1914)", en María Luisa Rodríguez-Sala et al. Independencia y Revolución: Contribuciones en torno a su conmemoración, México, unam-Instituto de Investigaciones Sociales, 2010, pp. 223-259. . Poder político y religioso, México, siglo XIX, t. 1, UnAM-Instituto de Investigaciones Sociales, México, 2010.

González Navarro, Moisés. Cristeros y agraristas en Jalisco, México, El Colegio de México, 2000, 2 vols.

González y González, Luis. Obras. El siglo de las luchas, México, El Colegio Nacional, 2002, t. 3.

Gutiérrez Casillas, José. Jesuitas en México durante el siglo XX, México, Porúa, 1981 (Biblioteca Porrúa, 77).

INEgi. Censos de Población y Vivienda, 1895 a 2010. Resumen del censo general. [Uia, Biblioteca Kino].

Junco, Alfonso. Un siglo de Méjico [sic]: de Hidalgo a Carranza, 2a. ed. aumentada, México, Ediciones Botas, 1937 (1934).

Katz, Friedrich. Pancho Villa, tr. Paloma Villegas, México, Era, 1998, 2 vols.

León XIII. "Rerum Novarum. Encíclica sobre el estado actual de los obreros”, 15/05/1991, en Encíclicas Pontificias: Colección Completa 18321959, Buenos Aires, Guadalupe 1965 (1891), t. 1: 1832-1939, 2 vols. 
Matute, Álvaro. "Historiografía del catolicismo social”, en Manuel Ceballos Ramírez y Alejandro Garza Rangel (coords.), Catolicismo social en México: teoría, fuentes e historiografía, Monterrey, Academia de Investigación Humanística, 2000, t. 1, pp. 29-74.

Quirk, Robert E. The Mexican Revolution and the Catholic Church, 19101929, Westport, Connecticut, Greenwood Press, 1986.

Ríus Facius, Antonio. Bernardo Bergoend, [sic] S. J.: guía y maestro de la juventud mexicana, México, Tradición, 1972 (La Verdadera Historia, 4).

Rodríguez Kuri, Ariel. Historia del desasosiego: la Revolución en la ciudad de México, 1911-1922, México, El Colegio de México-Centro de Estudios Históricos, 2010.

Valverde Téllez, Emeterio. Bio-bibliografía eclesiástica mexicana (1821-1943), dir. y pról. de José Bravo Ugarte, S. I., México, Jus, 1949 (Colección de estudios históricos), 3 vols.

Womack Jr., John. "La Revolución mexicana”, en Anna Timothy, Historia de México, tr. castellana, 2a. ed., Barcelona, Crítica, 2003 (1985), pp. $147-214$.

\section{Hemerografia}

Barbosa Guzmán, Francisco. "La Iglesia en la encrucijada de la Revolución mexicana”, Boletín Eclesiástico del Arzobispado de Guadalajara, Guadalajara, noviembre 2010, pp. 744-770.

Bravo Ugarte, José, S. I. "Antecedentes y primeros años de la Provincia Restaurada 1816-1913”, Noticias de la Provincia de México (México), septiembre-octubre 1957, pp. 260-277.

Compañía de Jesús. Noticias de la Provincia de México, México, 1910-1919; 1995 y 2015.

El Estudiante, órgano del Centro de Estudiantes Católicos, septiembre 1911, núm. 1, mayo 1913, s/n.

Fernández del Campo, José María, S. I. “¿Qué cosa es la Unión de Damas Católicas?”, Acción y Fe (México), t. II, núm. 1, 1924 (01/01/1924), pp. 48-53.

Gavin, Joseph B. "La enseñanza social católica: 1891-1975”, Promotio Iustitiae 66, dedicado a "De la Rerum Novarum al Decreto 4" (Roma), febrero 1997, p. 3. pp. 3-8.

"Informe presentado por la АСЈM en el Congreso Internacional de la Juventud Católica en Roma: Septiembre, 1921”, Acción y Fe [antes El Mensajero Mariano] (México), t. 1, núm. 1., 2a. Serie: enero 1922, pp. 45-48. 
"Las Congregaciones de San Luis Gonzaga: Apunte Histórico", El Mensajero Mariano (México), t. Iv, núm. 2, febrero 1921, pp. 72-117.

Meyer, Jean. Historia de los cristianos en América Latina, siglos XIX y XX, tr. Tomás Segovia, 1a. reimpr., México, Editorial Vuelta, 1991 (1989).

Ocampo, Manuel, S. I. "La Provincia de México de 1914-1929”, Noticias de la Provincia de México (México), septiembre-octubre 1957, núms. 232 y 233.

Palomar y Vizcarra, Miguel. "Ha muerto el Padre Bergoënd", Reconquista, Órgano Oficial de la Liga Nacional Defensora de la Libertad, s/l, octubre de 1943, núm. 14. (III, Correspondencia, Difuntos, Caja: 4 BaZ-Bo, Expediente: Bergoënd Lachenal Bernardo, Documento: Kardex). [Se anota la referencia de la Sección donde se encuentran en el AHPM].

Tesis

Baca Prieto, Imelda. "La intelectualidad estudiantil a principios del siglo xx. El caso de la Unión Nacional de Estudiantes Católicos”, tesis para obtener el grado de doctor en Historia, Universidad Iberoamericana, México, 2004.

Reich, Peter Lester. "Mexico's Hidden Revolution: The Catholic Church in Politics Since 1929”, Ph. D. dissertation, University of California, Los Angeles, 1991.

\section{Entrevistas}

Rodríguez Jiménez, Rafael Ignacio. Entrevista a Xavier Cacho Vázquez, S. I., historiador, México, D. F., 20/06/2007.

\section{Fuentes de internet}

GEA Gran Enciclopedia Aragonesa. “Aznar y Embid, Severino”. Disponible en: $<$ http://www.enciclopedia-aragonesa.com/voz.asp?voz_id=1692>. Consultada el $1^{\circ}$ septiembre de 2015.

—. "Severino Aznar, la pluma del águila de Tierga". Disponible en: $<$ http://www.arbil.org/(44)azna.htm RevistaARBIL, no 44 >. Consultada el $1^{\circ}$. de junio de 2019.

- "Los orígenes de la Democracia Cristiana". Disponible en: $<$ http://www.chasque.net/pdc/cayota.htm>. Consultada el $1^{\circ}$. de junio de 2019. 